\title{
A Study of the Impacts of Variable Factors on Built Environment Graduates' Prospects
}

\author{
Joanna Poon, BSc (Hons), MSc, \\ MA, PhD, MCIOB, FHEA \\ School of the Built Environment, \\ University of Salford, M5 4WT, \\ Greater Manchester, United Kingdom \\ Email: j.1.k.poon@salford.ac.uk
}

\author{
Michael Brownlow, BSc (Hons), \\ MSc \\ Department of Information \\ Technology, Vesuvius, S43 4XA, \\ Chesterfield, United Kingdom \\ Email: mjbrownlow@gmail.com
}

\begin{abstract}
This paper investigates the impacts of variable factors, such as practical experience and factors related to study style, on employment outcomes and patterns of built environment graduates in Australia. This paper also compares the employment prospects of different built environment sub-disciplines, including Architecture, Construction, Real Estate and Urban Planning and Regional Studies. Practical experience and the possibility of work with final year employers after graduation were found to have a statistically significant impact on the employment outcomes for graduates of built environment and all of its subdisciplines. However, degree level and type of university attended were not found to have a statistically significant impact. Attendance type and employment mode in the final year of study had a statistically significant impact on the employment patterns for graduates of built environment and all of its subdisciplines. The graduates who studied part-time and worked full-time in their final year of study were more likely to secure full-time jobs after graduation. The findings of this paper can be used by built environment graduates to identify the variable factors which they can change in order to enhance their employment prospects.
\end{abstract}

Key words: Australian Graduate Survey (AGS), Built environment, Employment prospects, Practical experience, Study style, Variable Factors

\section{Introduction}

Transition to employment after graduation has been a popular topic in different countries for the last several decades (Ballarino, 2009). In the UK, the government report, such as Browne (2013), has repeatedly highlighted the importance of employability. Employability has become an even more important issue in the UK since 2012 as university tuition fees were increased to a maximum of $£ 9,000$. Degree applicants have become more concerned about their employability due to the larger financial commitment. Similarly, universities also pay more attention to graduate employability as it is a major selection criterion for students when choosing a university or course. The Australian Government has also placed greater emphasis on graduate employability since the 2000s. DEST, ACCI and BCA (2002) identified new requirements for generic employability competencies that industry requires or will require in the foreseeable future. This report also provides clear definitions of employability skills within Australian industries. DIICCSRT and DEEWR (2013) developed the Core Skills for Work (CSfW) Development Framework, which is a set of employability skills or non-technical skills, knowledge and understandings that underpin successful participation in work.

Graduate employability is also a popular research topic in academia. There were studies investigating the development of employability skills during the study of university programmes 
(Ballarino, 2009; Finch et al., 2013; Pavlin, 2014). Ballarino (2009) used multivariate analysis to identify the effect of fields of study on the university-to-work transitions in Italy from 1995 to 2004. Palvin (2014) explored perceptions by senior professors and managers in higher education about their role in preparing graduates for entry into the labour market. Finch et al. (2013) used quantitative and qualitative approaches to gain an understanding of the seventeen identified factors influencing new graduates' employability. The development of employability skills is particularly relevant to vocational and professional accredited courses.

Practical experience is one of the most commonly mentioned employability skills in literature. Research also discussed the importance of employers offering opportunities for students to gain practical experience during their study (Callanan \& McCarthy, 2003). However, these studies are theoretical and prescriptive, and there is a lack of empirical evidence supporting these theoretical propositions (Finch et al., 2013). In addition, these studies have a heavy reliance on case studies or use data from a single organisation. They suffer from lack of generalizability, which makes it difficult to extrapolate or compare findings (Palvin, 2014).

There are numerous studies on the impact of demographic variables on employability which graduates cannot easily change. These demographic variables include gender (Fielden et al., 2000), age (Devaney \& Roberts, 2012) and ethnic background (Lim, 2010). However, there is as yet no research which focuses on investigating variable factors, which are the factors that graduates can change during their study in order to enhance their employability.

Despite extensive studies there is a lack of research examining the impact of demographic variables on graduate employment. . Furthermore, there is a lack of research of this type with an Australian focus. The variable factors identified in this research include factors related to study style, such as attendance type, mode of study, degree levels and types of university attended, as well as practical experience. The practical experience considered in this paper is whether graduates had paid work, either full-time or part-time, in the final year of study. The paid work defined in the Australian Graduate Survey (AGS) is any type of paid work, regardless of whether this is relevant to the subjects which the graduates studied or not. This paper also considers whether the possibility of work with final year employers can be another factor which enhances graduates' employment opportunities. This paper also investigates whether degree subjects have an impact on graduate employment outcomes and patterns. The built environment sub-disciplines considered in this paper include Architecture, Construction, Real Estate and Urban Planning and Regional Studies.

The aim of this research is to look at the impact of factors related to the study style and practical experience which will enhance graduates' employment prospects.

The paper aims to address the following research questions:

- What are the differences in the variable factors for graduates from different built environment sub-disciplines?

- What are the differences in employment outcomes and patterns for built environment graduates who have different factors related to their study style?

- What is the influence of practical experience on built environment graduates employment outcomes and patterns? 
- What is the influence on graduates' employment prospects where there is the possibility of work with final year employers after graduation?

\title{
Variable Factors Which Affect Graduates' Employment Prospects
}

\author{
Factors Related To Study Style
}

Degree subject is a well-identified factor which influences graduate employment (Ballarino, 2009; Lim, 2010; Smith et al., 2000). Lim (2010) studied the employment pattern of graduates of undergraduate degree programmes in the University of Utara Malaysia. He identified Accounting graduates had the highest employment rate whilst Information Technology graduates had the lowest employment rate and the highest number of days of being unemployed. Other business degree graduates, such as Business Administration, Public Management and other managementrelated degrees also had relatively high unemployment rates and suffered longer periods of unemployment. Ballarino's (2009) study found that graduates of quantitative subjects and Hard Sciences, such as Chemistry, Physics and Mathematics, had the highest employment rate and also had better terms of employment. This was followed in order of rank by Technical subjects, such as Engineering, Hard Social Sciences, Soft Social Sciences, Law and Humanities.

The type of university which the graduates attended also had an influence on the employment prospects of new graduates (Devaney \& Roberts, 2012; Finch et al., 2013; Urwin \& Di Pietro, 2005). Urwin and Di Pietro's (2005) research found that the postgraduate students, the students who studied in Graduate School in the USA context, who graduated from institutions with a stronger research culture had and enhanced employment rate.

Hoxley et al.'s study (2011) studied the difference in the employability of undergraduate and postgraduate students. This research reported that real estate undergraduates had gained higher levels of employability competencies than their postgraduate counterparts. Apart from this, there is no previous study focused on comparing the difference in employability for undergraduate and postgraduate students. Previous studies did not compare if the level of degrees, i.e. undergraduate or postgraduate, had an impact on graduate employability as they mainly focused on one type of degree. For example, Lim (2010), Smith et al. (2000) focused on studying undergraduate courses while Devaney and Roberts (2012) and Urwin and Di Pietro (2005) focused on investigating employability for graduates for postgraduate courses only.

There is only one study Smith et al. (2000) which investigated whether attendance type, which is full-time or part-time study, had an impact on graduate employment. Their conclusion was that it did not. Mode of study, which is distance, on-campus or mixed mode study, had an impact on student satisfaction (Douglas et al., 2006), but there is not yet any previous literature investigating its impact on graduate employment outcomes and patterns.

\section{Practical Experience}

Practical or pre-graduate work experience is an important factor for graduate employability and supporting graduates' transition from university to employment (Poon \& Brownlow, 2014; Poon 
et al., 2011). Practical experience defined in the previous literature includes different types of work experience which provides an indicator of the graduates' work ethics and may be translated to transferrable skills for any type of future employment, and not necessarily related to the subject the graduates studied.

Pre-graduate work experience may include in-programme experiential learning opportunities (e.g. co-op and internships) or more informal career-related work experience such as part-time or summer employment. Based on a study of 142 recent university graduates, Gault et al. (2000) commented that students who completed internships reported both higher job acquisition skills and job satisfaction, they further concluded that 'experiential education plays a vital role in enhancing the preparation and success of undergraduates in the entry-level job market' (p. 52). The research findings of a study focused on Canada, which used both the qualitative and quantitative methods also illustrated that prospective employers placed a high value on graduate job-seekers having internship or placement experience (Finch et. al., 2013).

There is also no lack of research investigating graduate employability in the built environment sector. Poon et al. (2011) used a mixed method approach, which included conducting questionnaire surveys with real estate professional practice employers and graduates, and interviews with RICS accredited course providers and the human resource managers of major surveying firms in the UK. One of the research findings from the questionnaire surveys suggested that both employers and graduates would like to see more practical skills and knowledge incorporated within the university curricula of real estate courses. Property professionals in Australia have also voiced the same concern; they stated practical experience is an important employability skill in Australia (Poon \& Brownlow, 2014). According to the findings of research to members of the Australian Property Institute (API), 98\% out of 252 of respondents agree or strongly agree that practical experience is an important skill in the property profession in Australia. This comment is also echoed by written comment, where 13 respondents stated this in the additional comment section (ibid.).

\section{Research Method}

\section{Data Source}

The data used in this paper has been collated from the Australian Graduate Survey (AGS) (AGS, 2015). AGS is a national census of newly-qualified higher education graduates that has been in operation since 1972. The survey is conducted approximately four months after the students have completed the requirements for their awards.

The data used in this paper dates from 2010 to 2012. Surveys conducted by the AGS prior to this were substantially different and therefore pre-2010 data is not compatible with this study and has not been used. The questions asked in the pre-2010 and post-2010 AGS questionnaire are different, some questions in the AGS questionnaire in earlier years were replaced with different questions in the 2010 questionnaire and the wording of some of the questions were changed. 
Other similar studies conducted in the UK, such as Smith et al. (2000) and Devaney and Roberts (2012), also used the government statistics on graduate destination. Smith et al. (2000) used First Destination Survey (FDS), conducted by Careers Offices of each university and deposited with the Higher Education Statistics Agency (HESA) and Devaney and Roberts (2012) used HESA Destination of Leavers from Higher Education (DLHE) dataset. Davaney and Roberts (2012) used a four year long data (2005/06 to 2008/9) while Smith et al. (2000) has only used one year (1983) data. Ballarion (2009) studied the difference in the employment outcomes of graduates who studied different degree subjects. He used the Italian National Statistical Institute (ISTAT) Graduates Employment Survey data. The current study used a similar type of government employment statistics from a three-year period.

\section{Validity Of Data}

Facing the same difficulties as Smith et al. (2000) and Davaney and Roberts (2012) who also used graduates' statistics produced by the government, such as the FDS dataset and the DLHE dataset respectively, the use of the AGS data is not without limitations. The first limitation is the incomplete response rate. The survey response rate for domestic graduates, which is the primary focus of the AGS, typically ranges from 60 to 65 per cent. There is no information on the response rate recorded for the overseas students. The second limitation is the timing of the survey. Graduates are invited to complete the survey four months after the completion of their courses, and this may be too early to conclude their employment situation.

Despite a less than complete response rate, the AGS is the most comprehensive graduate survey in Australia and provides detailed information on a large enough sample of university graduates to produce a statistically sound data analysis. Furthermore, gaining employment within six months is a good indicator for measuring graduate labour market difficulties (McKnight, 1999). McKnight's (1999) commented that graduates who remain unemployed after six months are typically unemployed for more than one year during the first 3.5 years after finishing their degree. This compares with an average duration of unemployment of one month for graduates who were employed within six months of graduation (ibid.). Although the AGS survey is completed four months after the graduates finish their degree, it can still provide an indication of their employment prospects.

\section{Data Preparation}

Dimensionality reduction was used to prepare the dataset for analysis in this paper, from the raw data of AGS. The R programming language was used to combine the three-years of AGS data (2010-2012) into one dataset. Dimensionality reduction is the process of reducing the number of random variables under consideration. The reason for dimensionality reduction in this paper was to conduct feature extraction. The data transformation within this project is linear, as in principal component analysis (PCA). The dimensionality reduction process of the AGS data within this paper reduces the number of columns in the dataset and replaces all of the columns in the data with a smaller number of columns that have a unique value for every row. Summary statistics were also used to produce a simpler classification of rows of data (Field et al., 2012).

After reviewing the course titles provided under AGS classification and the written information 
about the Course Majors which graduates studied, the classification for built environment courses was produced including Architecture, Construction, Real Estate and Urban Design and Regional Planning. Please see Table 1 for further information on the types of courses included under each category. In addition, the authors also reviewed information contained in the columns, which states the graduates' Course Majors (up to four majors can be identified) and identifies the graduates who studied built environment-related courses and included them into the respective groups together. If the graduates indicated that they were studying more than one course major, the authors have grouped them according to information based on their Course Major One.

In total, there are 9206 built environment graduates in 2010-2012. Of them, 4156 studied Architecture, 2011 studied Construction, 1258 studied Real Estate and 2117 studied Urban Design and Regional Planning. A number of built environment graduates studied double or triple majors with more than one built environment discipline, therefore, they have been counted in the individual courses which they studied but only once in the overall built environment category.

\section{INSERT TABLE 1 HERE}

The majority of the respondents to the AGS are Australian home-based students. Therefore, the authors have made the decision to only include the graduates who were Australian Permanent Residents in this study. The second reason for suggesting this arrangement is that there is a legal restriction for non-Australian Permanent Residents seeking appointment in Australia and it would distort the results if they were included in the analysis. Also, it is important to exclude the graduates who declared they were continuing on to further study as they were unlikely to seek full-time employment. After taking these into consideration, there are 5909 (64\%) built environment graduates considered in this study. Among them, 2119 (51\%), 1475 (73\%), 991 (79\%) and 1522 (73\%) are Architecture, Construction, Real Estate and Urban Design and Regional Planning graduates. Please see Table 2 for detailed information of built environment graduates who were Australian Permanent Residents.

\section{INSERT TABLE 2 HERE}

\section{Classification Of Variable Factors}

University types include old and new universities. Old universities are those established in Australia before 1900. New universities are institutions that were established or became accredited universities on or after 1900. The years for university establishment and becoming accredited are indicated in Australian Education Network (AEN, 2015).

Levels of degree considered in this paper are undergraduate and postgraduate degrees. As this study focused on investigating the employment outcomes and patterns of graduates from taught degree courses only, the graduates studying postgraduate research degree programmes were excluded from this study.

The other variable factors studied in this paper, such as attendance type, mode of study, practical experience, had full-time or part-time work in their final year of study or whether they had work 
with final year employers, have already been presented in a way which can be used for further analysis in this paper. In other words, the authors do not need to conduct any data preparation for this data, such as using dimensionality reduction to reduce the number of variables, as the variables presented in the AGS are already simplified enough to be used in the paper.

\section{Data Analysis}

Descriptive and statistical analysis methods have been used to assess the impact of factors on employment outcomes and patterns of built environment graduates in this paper. Descriptive statistics techniques were used to identify the impact of variable factors on employment outcomes and patterns of graduates who studied different built environment courses. The discussions of the comparison of employment outcomes and patterns for graduates who studied in different types of built environment courses were also presented. The distribution of the built environment and their sub-discipline graduates for each of the variable factors are reported in Appendix A. The employment outcomes and patterns for the number and percentage of graduates who have different variable factors (see Appendices B and D) so as their respective employment to population ratios are also presented (see Appendices $\mathrm{C}$ and $\mathrm{E}$ ).

The $\mathrm{R}$ programming language was also used to conduct the statistical analysis of this research. The statistical significance of the influence of variable factors on the employment outcomes and employment patterns of the built environment graduates and among the graduates from different built environment sub-disciplines were identified. Chi-Squared Contingency 2-way analysis was used to conduct the data analysis in this research. The reason for using the 2-way analysis is to ensure the accuracy of the result. If the calculated value of the Chi-square test statistic is more than the critical value of 3.841, which is equivalent to a 0.05 significance level, the null hypothesis is rejected. The critical value of 3.841 is used since it represents the critical value for a chi-square with 1 degree of freedom. The null hypothesis is that the two variables, i.e. variable factors and employment outcomes or employment patterns, are independent of each other. If the null hypothesis is rejected, it means that the two variables are not independent of each other (Field et al., 2012).

The phi coefficient was used to measure the correlation between the employment outcomes and employment patterns against individual variable factors. The phi coefficient was chosen as it is designed for the comparison of truly dichotomous distributions, i.e., distributions that have only two points on their scale which indicate some unmeasurable attribute. The value of the phi correlation coefficient ranges from -1 to +1 , where $+/-1$ indicates perfect correlation between two variables and 0 indicates no relationship between two variables (Field et al., 2012).

Despite some missing data, being that the respondents did not provide a clear and defined answer which indicated their study type or employment, for the variable factors, such as attendance type, have paid work at final year, work full-time or part-time in the final year of study and work with final year employer after graduation, their sizes are insignificant and they are excluded in the analysis. For mode of study, only distance and on-campus study are considered in the ChiSquared Contingency 2-way analysis. 


\section{Research Findings And Discussion}

\section{Identify the Differences In The Variable Factors For Graduates From Different Built Environment Sub-disciplines}

The majority (75.53\%) of the built environment graduates studied full-time. Among the four subdisciplines, the Architecture graduates had the highest percentage of graduates who studied fulltime, which was $86.50 \%$. Urban Design and Regional Planning had the lowest percentage of graduates studying full-time, there were only $61.17 \%$ studying full-time.

The dominant study mode was on-campus, $82.04 \%$ of built environment graduates studied in this mode. There were a nearly equal proportion of built environment graduates studying in distance mode and mixed mode, their percentages were $9.38 \%$ and $8.41 \%$ respectively. Same as attendance mode, Architecture was the built environment sub-discipline which had the highest percentage of graduates studying in on-campus mode, at $92.26 \%$. There were only $1.75 \%$ of Architecture graduates studying in distance mode, which was $7.63 \%$ lower than the built environment graduates who studied in distance mode. On the other hand, the Urban Design and Regional Planning discipline had the lowest percentage of graduates studying in on-campus mode, which was $74.84 \%$, whilst it had the highest percentage studying in distance mode, which was $15.57 \%$.

There were $60.60 \%$ built environment graduates studying undergraduate degrees. Construction had the highest proportion of graduates studying undergraduate degrees and the percentage is $85.76 \%$. On the other hand, Architecture had the higher percentage of graduates studying postgraduate degrees, the percentage is $55.21 \%$. It is because Architecture students had to study for a Masters Degree before they were able to be get exemption for the written examination to fully qualify as architects.

The majority of built environment graduates studied in new universities; the percentage is $80.32 \%$. Nearly all real estate graduates $(98.49 \%)$ were studying in new universities.

Architecture was the discipline which had the highest percentage of graduates studying in old universities, which was $34.92 \%$.

The majority of built environment graduates $(81.32 \%)$ had paid work in their final year of study. Architecture graduates were the least likely at $77.25 \%$ to have paid work during their final year of study. At the same time, Architecture was the discipline which had the highest percentage of graduates who declared they did not have paid work in their final year of study, at $22.37 \%$.

Almost half of the built environment graduates (47.62\%) worked on a part-time basis during their final year of study. Architecture was the sub-discipline which graduates were more likely to work on a part-time basis, $63.43 \%$ worked part-time as compared to only $13.59 \%$ of them working full-time.

More than half of the built environment graduates (52.38\%) worked for their final year employers after graduation while $28.62 \%$ of graduates declared they did not work for their final year employers. Architecture graduates were less likely to work for their final year employers. 
Only $44.88 \%$ of Architecture graduates declared they worked for their final year employers whilst $31.95 \%$ said they did not.

\section{Identify The Differences In Employment Outcomes And Patterns For Built Environment Graduates Who Have Different Factors Related To Their Study Style}

\section{Difference In Employment Outcomes}

This section discusses the difference in employment outcomes i.e. whether the graduates were employed or not at the time they were surveyed by the AGS. Out of the 5909 built environment graduates who were Australian Permanent Residents and declared they were not to carry on with further study at the time which the AGS was undertaken, $88.41 \%$ were employed at the time when the AGS was conducted while $11.10 \%$ were not working (see Appendix B). Among the four built environment sub-disciplines, the Architecture graduates had the lowest percentage of graduates who gained employment, at $84.66 \%$. On the other hand, the Construction graduates had the highest employment level and their employment rate was $92.27 \%$. This finding echoed Lim (2010), McKnight (1999) and Smith et al. (2000)'s research findings, that degree subject was a factor influencing graduate employment. The current study shares the same finding and indicates certain built environment graduates, such as Construction graduates, were more likely to secure graduate employment.

The employment prospects for built environment graduates who studied full-time are not as good those who studied part-time. Graduates who studied at part-time mode were likely to work fulltime when they studied their degrees. They were more likely to secure employment after graduation as they were already employed or had practical experience which enhances their employment prospects. This was demonstrated in the employment to population ratios. The employments to population ratios for full-time and part-time and full-time built environment graduates were $87.03 \%$ and $92.70 \%$ respectively. This finding was statistically significant as the chi-square value was 38.0765, which was higher than the critical value of 3.841 (see Appendix F) and the phi coefficient value was -0.08 (see Appendix G). Attendance mode also had an impact on Architecture and Urban Design and Regional Planning graduates' employment outcome and it was statistically significant as the chi-square values were 21.7687 and 10.8198 (see Appendix F) and the phi values were -0.1 and -0.09 (see Appendix G). The employment to population ratios for Architecture graduates who studied in full-time and part-time modes were 83.31\% and 93.59\% respectively, while for Urban Design and Regional Planning graduates were $86.68 \%$ and $92.03 \%$ respectively (see Appendix C). Among the four built environment subdisciplines, Construction graduates were most employable, the employment to population ratios for full-time and part-time construction graduates were $91.97 \%$ and $93.33 \%$ respectively (see Appendix C) but the finding were not statistically significant as the chi-square value was 0.6718 (see Appendix F). This finding is different from Smith et al.'s (2000) which indicated study mode had no impact on graduate employment outcomes.

Mode of study also has an impact on graduate employment outcome. The unemployment rate for graduates studying in distance mode was lower. There were $9.38 \%$ of built environment graduates studying in distance mode while only $4.57 \%$ were unemployed (see Appendices A and B). It made employment to population ratios for the built environment graduates who studied in 
distance mode at $94.04 \%$, as compared to $87.69 \%$ for the graduates who studied in on-campus mode (see Appendix C). The difference was statistically significant as the chi-square value for built environment graduates who had different study modes is 20.0886 with a phi coefficient value was 0.06. It was the same case for Urban Design and Regional Planning graduates, those who studied in a distance mode were more likely to secure employment than those who studied in an on-campus mode, their employment to population ratios were $93.67 \%$ and $88.15 \%$ respectively (see Appendix $\mathrm{C}$ ). Their difference was statistically significant as the chi-square value was 7.3014 and the phi coefficient value was 0.08 . An explanation is that the graduates who studied in a distance mode were already employed whilst they studied; therefore, they are more likely to still be employed after finishing their degree. Overall, construction graduates were the most likely to have secured employment after graduation as the employment to population ratio for the graduates who studied in different study modes, such as distance, on-campus and mixed mode, were higher than other built environment disciplines at 95.97\%, 91.60\% and $93.51 \%$ respectively. However, this finding was not statistically significant as the chi-square value was 2.2764 (see Appendix F).

Degree level and type of university attended did not have statistically significant impacts on the employment outcomes of built environment graduate employment at all as the chi-square value for built environment and all sub-disciplines graduates were smaller than 3.841. This contrasted with the comment from Devaney and Roberts (2012) and Urwin and Di Pietro's (2005) research, which is type of university attended, had an impact on employment outcome.

\section{Difference In Employment Patterns}

This section discusses the difference in employment patterns, which is whether the graduates were employed on a full-time or part-time basis after graduation. The majority of built environment graduates $(71.69 \%$ ) were employed on a full-time basis while $16.72 \%$ were employed on a part-time basis. Architecture had the lowest percentage of graduates employed on a full-time basis, at $60.50 \%$, and the highest percentage of graduates employed on a part-time basis, at $24.16 \%$. It is the opposite picture for Construction graduates, which had higher percentages of graduates $(84.14 \%)$ employed on a full-time basis while $8.14 \%$ of graduates were employed on a part-time basis (see Appendix D).

Attendance mode had an impact on graduate employment patterns. This was statistically significant for the graduates of built environment and all of its sub-disciplines, who studied on a part-time basis, they were more likely to secure full-time employment and their chi-squared values were more than the critical value of 3.841 and the phi coefficient values were negative. There was a low negative relationship between attendance mode and employment pattern for Real Estate graduates as the phi coefficient value was -0.15 while there was a negligible negative relationship for built environment and other three sub-disciplines as their phi coefficient were 0.09 or less (Field, 2012). The difference in the employment to population ratios for built environment and its sub-disciplines graduates who studied in different attendance modes and were employed on a full-time basis ranged from $6.48 \%$ to $15.89 \%$. Construction graduates had the smallest difference in employment to population ratio for graduates who studied in part-time and full-time modes and the Architecture graduates had the biggest difference (see Appendix E). 
Mode of study had statistically significant impacts on the employment patterns for built environment and Construction graduates as their chi-square values were 17.2896 and 5 respectively. The graduates who studied in a distance mode were slightly more likely to gain full-time employment than those who studied in an on-campus mode as their phi coefficient values were 0.06 and 0.07 respectively. The employment to population ratios for built environment graduates who studied in distance and on-campus modes and employed on a fulltime basis were $82.67 \%$ and $70.30 \%$ while for Construction graduates it was $92.62 \%$ and $82.86 \%$ (see Appendix E).

Degree levels had a statistically significant impact on the graduate employment patterns for Architecture and Real Estate graduates as their chi-square values were 37.1349 and 10.06 respectively. Their phi coefficient values were -0.15 and -0.11 , which means the postgraduate graduates of these two sub-disciplines were more likely to secure full-time employment. The employment to population ratios for Architecture undergraduates and postgraduates who gained full-time employment were 53.64\% and $66.07 \%$, while the ratios for Real Estate undergraduates and postgraduates were $75.27 \%$ and $84.31 \%$. As mentioned in Section 4.2.1, the reason for postgraduate Architecture graduates to secure employment because they were required to have a postgraduate degree qualification in order to seek an architecture role. The finding of this study echoed Poon et al.'s (2011) finding, that postgraduate real estate graduates were more likely to secure employment than their undergraduate counterparts.

Type of university attended also had a statistically significant impact on employment patterns for the built environment graduates. The built environment graduates who studied in new universities were more likely to get full-time employment. The chi-square value was 22.7136 and the phi coefficient value was 0.07 (see Appendices F and G). The employment to population ratios for built environment graduates from new universities and old universities were $73.11 \%$ and $65.86 \%$ respectively (see Appendix E).

\section{Identify The Influence Of Practical Experience On Built Environment Graduates Employment Outcomes And Patterns}

Graduates who had paid work in their final year of their study, regardless of whether it was a part-time or full-time job, had a statistically significant impact on employment outcomes for built environment and all of its sub-disciplines graduates as the chi-square values were more than the critical value of 3.841. The chi-square values for having paid work in the final year of study and employment outcomes for graduates of built environment and its sub-disciplines ranged from 95.7736 to 883.2193 and their phi coefficient values were from 0.32 to 0.45 (see Appendices $\mathrm{F}$ and $\mathrm{G}$ ), which indicates a moderate positive relationship existed between having paid work in the final year and employment outcomes for the graduates. There were significant differences in the employment to population ratios for the graduates of built environment and the sub-disciplines who did and did not have paid work in their final year of study. The employment to population ratios for graduates of built environment, Architecture, Construction, Real Estate and Urban Design and Regional Planning who had paid work in the final year of study were $94.30 \%$, $92.24 \%, 95.97 \%, 94.96 \%$ and $94.64 \%$ respectively. Those who did not have paid work in their final year of study were at $62.14 \%, 58.65 \%, 69.70 \%, 71.66 \%$ and $54.87 \%$ respectively (see Appendix C). In other words, the difference in the employment to population ratios for graduates 
who had and did not have paid work in their final year of study were $32.16 \%, 33.59 \%, 26.27 \%$, $23.30 \%$ and $39.78 \%$ respectively. This result further reinforced Finch et al. (2013) findings on the importance of practical and pre-graduate experience on graduate employability.

Having full-time work in the final year of study had a statistically significant impact on graduates of built environment and all of its sub-disciplines chance of gaining employment after graduation as their chi squares were from 5.0505 to 54.8847 (see Appendix F). Their phi coefficient values were 0.06 to 0.13 (see Appendix G). Working full-time in the final year of study also had a statistically significant impact on the employment patterns of built environment and the sub-discipline graduates as their chi-square values ranged from 91.8906 to 595.4421 and their phi coefficient values are from 0.25 to 0.43 , which indicates there was a low to moderate positive relationships between the two variables. The graduates who worked full-time in the final year of study were more likely to be employed on a full-time basis after graduation. One of the explanations is that these graduates were already working full-time during their degree and they carried on the same employment type after graduation.

Having paid work in the final year of study had a statistically significant impact on the employment patterns for built environment and Construction graduates only, as their chi square values were 4.0199 and 3.8995. Their phi coefficient values were 0.03 and 0.06 , which means the graduates who worked full-time in the final year were more likely to be employed in a fulltime role after they finished their degree.

\section{Identify The Influence On The Possibility of Work With Final Year Employers After Graduation On Graduates’ Employment Prospects}

Possibility of work with final year employers had a statistically significant impact on the employment outcome for the graduates of built environment and all the sub-disciplines, their chisquare values ranged from 55.7914 to 373.5937 (see Appendix F). Their phi coefficient values were from 0.24 to 0.31 (see Appendix G), which indicated a moderate positive relationship existed between these two variables (Field, 2012). This finding echoed Love et al. (2001) and Palvin (2014)'s comment on the importance of employers' contribution in enhancing graduate employability.

Built environment and architecture graduates' possibilities to work with final year employers also had a statistically significant impact on their graduate employment patterns as the chi square values were 16.0696 and 19.5582. Their phi coefficient values were -0.06 and -0.12 , which meant these two variables had negligible and low negative relationships. In other words, the built environment and Architecture graduates were more likely to be employed on a part-time basis after graduation by their final year employers. This finding aligned with another finding of this research, which is that Architecture had the highest percentage of graduates employed on a parttime basis after graduation, at $24.15 \%$ (see Appendix D). Please see Appendix H for summary of research findings and discussion.

\section{Conclusion}


This paper investigated the influence of variable factors, including attendance type, mode of study, degree levels, types of university attended and practical experience, on the employment outcomes and patterns of built environment graduates in Australia. This paper also compared the difference of employment outcomes and patterns for different built environment sub-disciplines, including Architecture, Construction, Real Estate and Urban Planning and Regional Studies. The measure of practical experience in this paper was whether graduates had paid work, either fulltime or part-time, in their final year of study. This paper also investigated whether possibility of work with final year employers after graduation would have an impact on the employment outcomes and patterns of graduates.

The quantitative data analysis methods for this research were chi-squared analysis and phi coefficient. Chi-squared analysis was used in order to investigate whether variable factors and employment outcomes or employment patterns, are independent of each other. The phi coefficient was used to measure the correlation between the employment outcomes and employment patterns against individual variable factors, which indicated the level of influence of individual variables on employment outcomes and patterns.

The employment rate for Architecture, Construction, Real Estate and Urban Design and Regional Planning are $84.66 \%, 92.27 \%, 90.41 \%$ and $88.76 \%$ respectively. There was a higher percentage of Construction graduates $(84.14 \%$ ) working full-time after graduation while a higher percentage of architecture graduates $(24.14 \%)$ were employed in part-time roles. There was also the highest percentage of Architecture graduates (14.77\%) who were neither working nor in further study after graduation.

Practical experience, regardless of full-time or part-time job, is an important factor for graduates from built environment and all of its sub-disciplines on gaining employment after graduation and the impact is statistically significant as the chi square values is larger than the critical value of 3.841 and the phi coefficient value is positive. Possibility of work with final year employers after graduation also had a statistically significant positive impact on built environment and all its subdisciplines graduate employment outcomes. On the other hand, degree level and the type of university attended did not have a statistically significant impact on employment outcomes for graduates of built environment and its sub-disciplines.

Attendance type and the employment mode in the final year of study had a statistically significant impact on the employment patterns for graduates of built environment and all of its sub-disciplines. The graduates who studied part-time and worked full-time in the final year of study were more likely to secure full-time jobs after graduation.

This research which has an Australian focus, reinforced the findings of previous Australianfocused studies such as Callanan and McCarthy (2003) and Love et al. (2001) on the importance of practical experience and employers' contributions on enhancing graduates' employment prospects. As part of the process for enhancing graduates employment opportunities, it is important for built environment course providers to find opportunities for students to gain practical experience as part of the curriculum. 


\section{Limitations Of This Research}

The first limitation is the generalizability of this research. Despite the response rate for AGS is quite high, of the ranges from $60-65 \%$, there is still concern on the representation of the overall population of Australian built environment graduates.

The second limitation of this research is that it cannot provide detailed analysis on whether the built environment graduates were able to find employment in the same sector due to data deficiency. The authors have conducted dimension reduction on the sectors of work at which the built environment graduates are employed. Six sectors were identified, which are architecture, construction, property, education, consultancy and other sectors. However, there are $49.15 \%$ of built environment graduates classified as working in others sectors. Giving the percentage of built environment graduates working in other sectors at nearly $50 \%$, it is unable to determine with confidence, the proportion of built environment graduates working in relevant sectors.

The third limitation is that the unknown number of extraneous variables, such as finances, family structure, motivation and self-efficacy, may impact employment and employability, but were not considered in this paper as they are not considered in the AGS dataset.

\section{References}

Australian Education Network (AEN) (2015). Historical development of Australian university sector [WWW document]. URL http://Www.australianuniversities.com.au/directory/history-ofaustralian-universities/.

Australian Graduate Survey (AGS) (2015). Australian Graduate Survey [WWW document]. URL http://www.graduatecareers.com.au/research/surveys/australiangraduatesurvey/.

Ballarino, G. (2009). Field of study and university graduates' early employment outcomes in Italy during 1995-2004. Labour, 23 (3), 421-457.

Browne, E. J. P. (2010). An independent review of higher education funding and student finance in England. London: HMSO.

Callanan, J. \& McCarthy, I. (2003). Property education in New Zealand: industry requirements and student perceptions. Journal of Real Estate Practice and Education, 6 (1), 23-32.

Department of Education, Science and Training (DEST), Australian Chamber of Commerce Industry (ACCI), \&Business Council of Australia (BCA) (2002). Employability skills for the future. Canberra, Australia.

Department of Industry, Innovation, Climate Change, Science, Research and Tertiary Education (DIICCSRT), \& Department of Education, Employment and Workplace Relations (DEEWR) (2013). Core Skills for Work Developmental Framework (CSfW). Canberra, Australia. 
Devaney, S. \& Roberts, D. (2012). Who gets the jobs? Factors influencing the employability of property and construction graduates in the UK. Construction Management and Economics, 30, 233-246.

Douglas, J., Douglas, A. \& Barnes, B. (2006). Measuring student satisfaction at a UK university. Quality Assurance in Education, 14 (3), 251-267.

Field, A., Miles, J., \& Field, Z. (2012). Discovering Statistics Using R. London: SAGE Publications Ltd.

Fielden, S. L. Davison, M. J., Gale, A. W. \& Davey, C. L. (2000). Women in construction: the untapped resource. Construction Management and Economics, 18, 113-121.

Finch, D. J., Hamilton, L. K., Baldwin, R. \& Zehner, M. (2013). An exploratory study of factors affecting undergraduate employability. Education and Training, 55 (7), 681-704.

Gault, J., Redington, J. \& Schlager, T. (2000). The benefits of undergraduate business internships: implications for the student, university, and business community. Journal of Marketing Education, 22 (1), 45-53.

Hoxley, M., Poon, J. \& Fuchs, W. (2011). Real estate employability: differing perceptions of graduates from undergraduate and postgraduate courses. Journal of European Real Estate Research, 4 (3), 243-258.

Lim, H. (2010). Predicting low employability graduates: The case of University Utara Malaysia. The Singapore Economic Review, 55 (3), 523-535.

Love, P. E. D., Haynes, N. S. \& Irani, Z. (2001). Construction managers' expectations and observations of graduates. Journal of Managerial Psychology, 16 (8), 579-593.

McKnight, A. (1999). Graduate employability and performance indicators: first destination and beyond; in Moving on: graduate careers three years after graduation. Manchester: DfEE/ IER.

Pavlin, S. (2014). The role of higher education in supporting graduates' early labour market careers. International Journal of Manpower, 35 (4), 576-590.

Poon, J. \& Brownlow, M. (2014). Competency expectations for property professionals in Australia. Journal of Property Investment and Finance, 32 (3), 256-281.

Poon, J., Hoxley, M. \& Fuchs, W. (2011). Real estate education: an investigation of multiple stakeholders. Property Management, 29 (5), 468-487.

Smith, J., McKnight, A. \& Naylor, R. (2000). Graduate employability: policy and performance in higher education in the UK. Economic Journal, 110 (June), F382-F411.

Urwin, P. \& Di Pietro, G. (2005). The impact of research and teaching quality inputs on the employment outcomes of postgraduates. Higher Education Quarterly, 59 (4), 275-295. 